\title{
First report of Nectria haematococca causing root rot disease of physic nut (Jatropha curcas) in China
}

\author{
Yue-kai Wu • Guo-teng Ou • Jin-yong Yu
}

Received: 23 November 2010 / Accepted: 7 April 2011 /Published online: 22 May 2011

(C) Australasian Plant Pathology Society Inc. 2011

\begin{abstract}
A serious root rot disease in nurseries and plantations of $J$. curcas has been observed in Luodian County, Guizhou Province, China, since 2006. The symptoms were yellowing, wilting and leaf fall as well as blackening and rotting of the roots and collars. Laboratory examination and greenhouse pathogenicity tests showed that the causal agent of the disease was Nectria haematococca. This is the first report of $N$. haematococca, as the cause of root rot of Jatropha curcas L. in China.
\end{abstract}

\section{Keywords Nectria haematococca $\cdot$ Jatropha curcas $\cdot$ Root rot}

As a potential biofuel plant species, physic nut (Jatropha curcas L.) has attracted great attention worldwide, with an increasing number of plantations in many tropical countries. In Luodian County of Guizhou Province, China, many nurseries and plantations of $J$. curcas have been affected by a serious root rot disease that has resulted in great damage and economic loss since 2006. In some investigated sites, the mortality rate of the seedlings was up to $40 \%-60 \%$. The number of seedlings cultivated in a greenhouse in Guizhou Academy of Forestry had also been infected with a mortality rate of $83.5 \%$ in 2009 . The main symptoms of the root rot disease included leaf yellowing, wilting and finally leaf fall, as well as blackening and rotting of the roots and collars, eventually leading to

\footnotetext{
Y.-k. Wu $(\bowtie) \cdot$ J.-y. Yu

Forest Resource Protection Institute,

Guizhou Academy of Forestry,

Guiyang, Guizhou 550005, China

e-mail: ten1972@163.com

G.-t. $\mathrm{Ou}$

Forestry Bureau of Loudian County,

Luodian, Guizhou 550100, China
}

plant death. The time from infection to death of infected plants was about 3-4 months. Jatropha curcas is a succulent and vigorous plant species with great potential for root regeneration. Consequently even if underground parts (roots, collars) were rotted, the above ground parts (stem, top leaves and buds) remained healthy for a limited amount of time (Fig. 1). These symptomatic characteristics made the detection of the disease difficult during the early stages of infection, making the disease hard to predict and manage.

The symptoms of root rot disease in our study were similar to that of root and collar rot disease caused by Lasiodiplodia theobromae (Pat.) Griffon \& Maubl. reported from India and Brazil (Latha et al. 2009; Pereira et al. 2009). In our case, root rot disease was mainly found on 0-3 year old seedlings and was usually associated with over watering or waterlogging. These conditions were found in nurseries with heavy soil types having poor drainage or if plants had been over-watered. Root rot was more common than collar rot, which was seen usually in the later stages of the disease. Another fungus, Fusarium moniliforme, which also causes root rot of Jatropha curcas was reported in India (Kaushik et al. 2001). There have been no similar reports in China so far.

In order to identify the causal agent of this important disease, a total of 80 diseased seedlings (1-3 year-old) were collected from 2006 to 2010, most of which from the field in Luodian and less from the greenhouse in Guizhou Academy of Forestry. Fresh diseased plant roots were thoroughly washed in running tap water, then rinsed twice with distilled water, and, just before isolation, surface sterilized by $75 \%$ alcohol. Small thin slices were cut at what appeared to be the advancing edges of the rot in the heart tissue of the roots, and they were transferred immediately onto the medium in tubes under aseptic 
Fig. 1 Symptoms of the root rot disease: even though the roots are damaged and rotted, the stem and the top leaves (buds) still keep fresh green, except older leaves dropped off (top left \& middle); some new roots regenerated, sustaining the diseased seedlings for a certain period of time (top right); appearance of the diseased roots in different infection stages (bottom left); disease usually develops through the pith (bottom right)

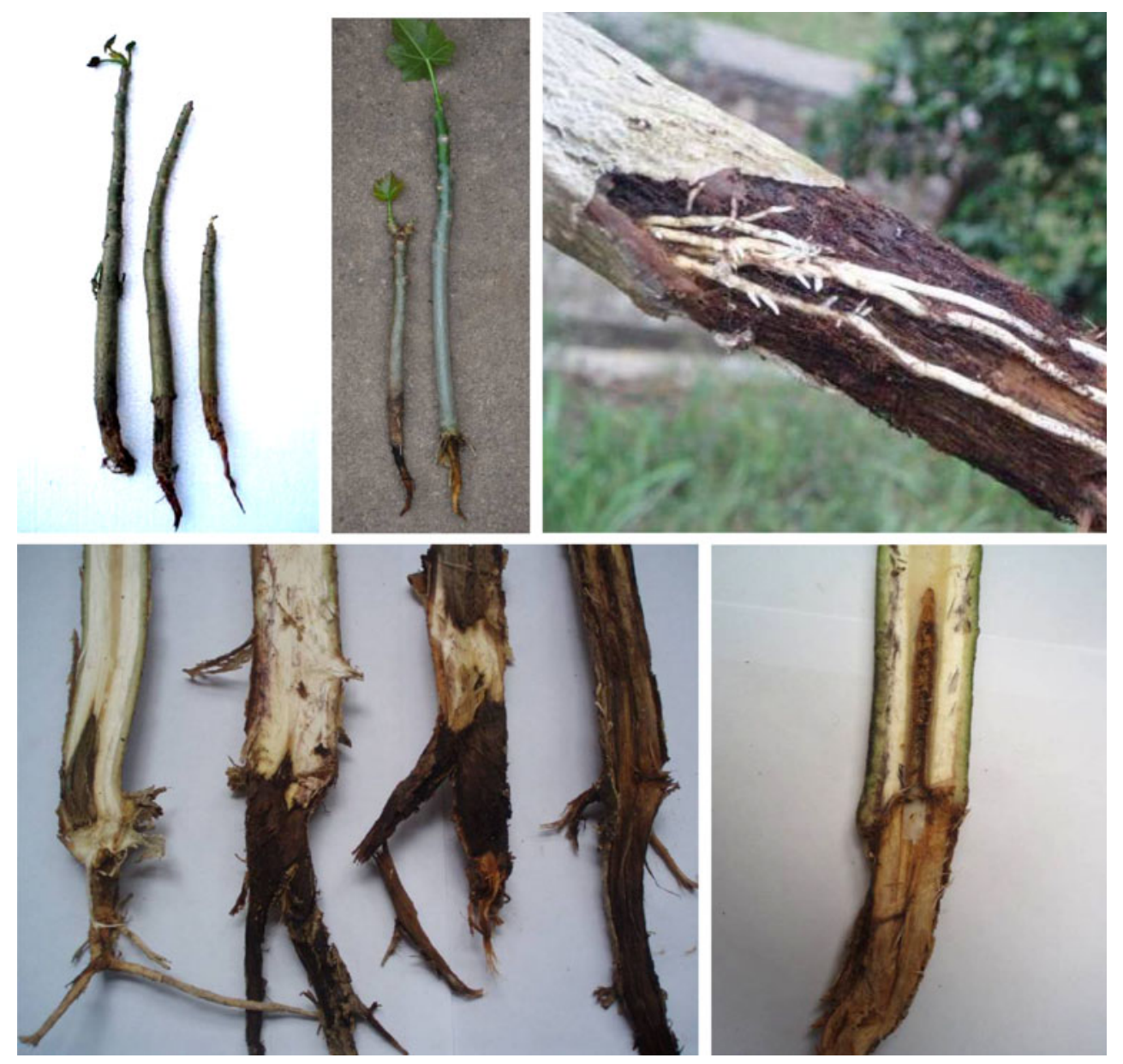

conditions. These tubes were then incubated at $28^{\circ} \mathrm{C}$. Pure cultures wee obtained by the mycelium tip culture technique. As a result, a total of 121 isolates with similar cultural characteristics and microscopic features were obtained (Fig. 2).

On PDA, the colonies grew quickly. Mycelium was dirty-white or pale vinaceous brown, usually floccose, and with slight green, blue, or bluish brown pigmentation when sporodochia formed. Pionnotes usually appeared as ochraceous, translucent colonies. Macroconidia were formed from short multi-branched conidiophores, cylindrical, slightly curved, with an indistinct foot cell and a blunt apical cell, usually 3 , sometimes 4 septate, seldom 2 or 5 septate, 4.3-6.7×23.5-46.0 $\mu \mathrm{m}$. Microconidia were nonseptate, sometimes one-septate, usually abundant, oval, fusiform, or cylindrical, 2.5-5.8 $\times 4.2-18.8 \mu \mathrm{m}$, usually produced from long (sometimes branched) phialides. Chlamydospores were terminal or intercalary, globose, brown, borne singly, sometimes in pairs or even in chains, 4.6-9.9 $\mu \mathrm{m}$ in diam., occurred abundantly especially on old culture stored in the refrigerator.

The teleomorphic stage (perithecia) of the fungus was occasionally found in the field. Numerous perithecia appeared on the collar region of the diseased seedlings as orange clusters. Perithecia were globose, usually gregarious, orange or scarlet, tuberculate, 200-500 $\mu \mathrm{m}$ in diam. The perithecial wall was pseudoparenchymatous, with cell walls pigmented and thickened. Asci were 8-spored, narrowly cylindrical, unitunicate, 44.5-72.5 ×6.4-9.2 $\mu \mathrm{m}$; ascospores mostly uniseriate, ellipsoid or fusiform with narrowly rounded ends, hyaline or slight olive-green, 1-septate, often constricted at septum, 4.0-5.8 $\times 9.7-$ $14.2 \mu \mathrm{m}$. The cultures that were isolated from the perithecia were pure white, and gregarious perithecia were readily produced, similar in size and color to the perithecia that formed naturally ones, except that they occurred among a byssoid subiculum (Fig. 3)

Twenty-five 1-year-old healthy seedlings grown in sterile soils in containers were used for pathogenicity testing of the isolated fungus. At the first step, four isolates with typical features of the fungus were randomly selected and cultured on PDA for 2 weeks at $28^{\circ} \mathrm{C}$, and then sexual and asexual spores were collected with distilled water to produce spore suspensions. Secondly, a sharp knife was used to make a scratch on the tap roots of the seedlings. Thirdly, $5 \mathrm{ml}$ of spore suspension of each isolate was 
Fig. 2 Microscopic characteristics of the pathogen: gross appearance of the culture in tubes (top left); Pionnotes usually appeared in the center of the culture (top middle); numerous macro and micro spores were produced from the hyphae layers (top right, bar $=10 \mu \mathrm{m}$ ); in old culture, different spores including macroconidia,microconidia, and chlamydospores are produced from the hyphae (bottom left; bar $=10 \mu \mathrm{m})$; microconidia are usually produced on long phialides (bottom middle; bar $=10 \mu \mathrm{m}$ );on old culture (cold stored for 4 months), a great number of chlamydospores were produced (bottom right; bar $=10 \mu \mathrm{m}$ )
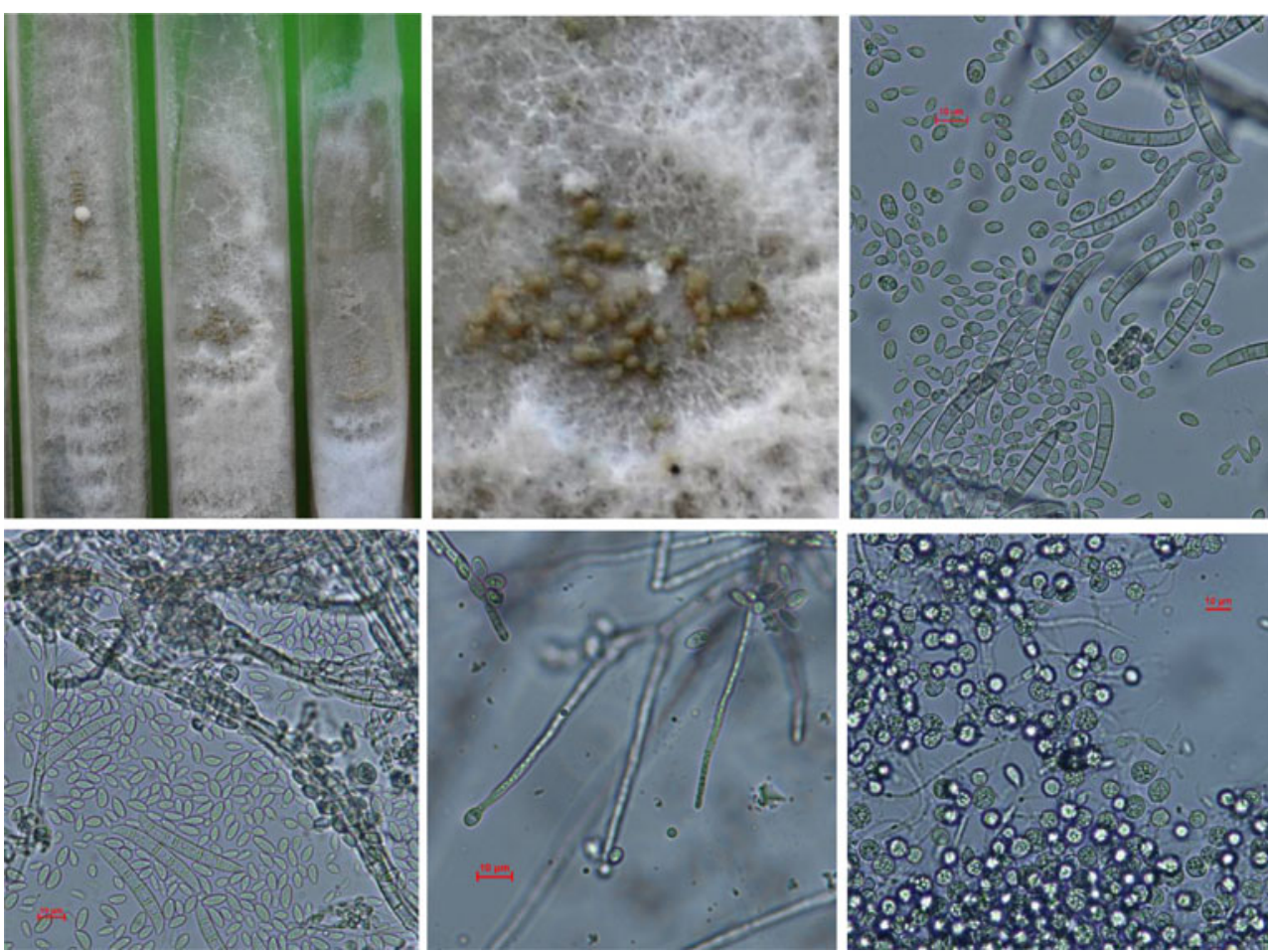

injected onto the wound root area of the seedling and then covered it with soil. Each isolate was inoculated on 5 seedlings by this way serving as a treatment, while other 5 seedlings treated with sterile distilled water served as control. All of the 25 seedlings were kept in the greenhouse at $18-30^{\circ} \mathrm{C}$ with regular watering, and each treatment was in a distance of $2 \mathrm{~m}$ from each other. After 2 months, 20 seedlings treated with spore suspensions of different
Fig. 3 Teleomorph of the causal agent: perithecia of $N$. Haematococca appeared on the collar region of the diseased seedlings (top left); larger magnification of the perithecia (top middle; bar $=100 \mu \mathrm{m}$ ); nearly-mature asci, each containing 8 ascospores (top right; bar $=10 \mu \mathrm{m}$ ); clustered perithecia produced on the culture (bottom left); perithecia are among a byssoid subiculum (bottom left); larger magnification of one perithecium (bottom right; bar $=50 \mu \mathrm{m}$ )
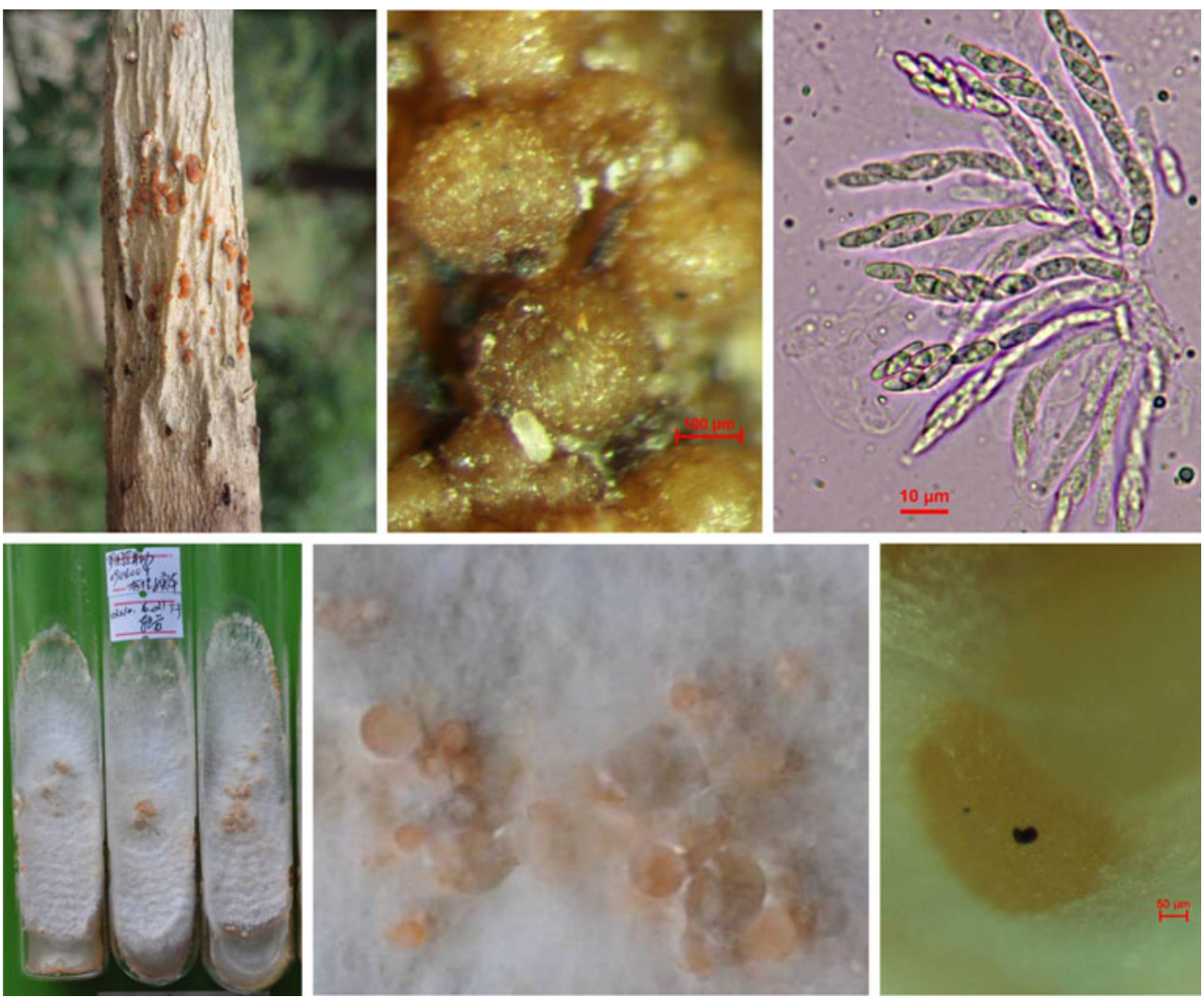
isolates all showed typical symptoms of the root rot disease (100\% infection): leaves yellowing and falling down, and the roots darkened and rotted, except the aboveground stem and the top leaves keeping green. Pure cultures of the reisolated organisms from the diseased roots had the same characteristics as the original ones. The other 5 seedlings treated with sterile distilled water all showed no typical symptom of the disease and their roots remained healthy and fresh $(0 \%$ infection). The result showed that all of the 4 tested isolates were pathogenic to the seedlings of Jatropha curcas.

According to results of the pathogenicity test, along with the culture appearance and microscopic structure of the isolated fungus, the causal agent of root rot disease of Jatropha curcas was identified as Fusarium solani (Martius) Appel \& Wollenweber, and its teleomorph was Nectria Haematococca Berk.\& Br.(Dingley 1951; Booth 1960, 1977; Wei 1979). Thus the causal agent of root rot disease occurred in China was definitely different from that of root rot disease in India, which was identified as Fusarium moniliforme (Kaushik et al. 2001).To the best of our knowledge, this was the first report of root rot disease of Jatropha curcas caused by Fusarium solani. Cultures of the pathogen have been deposited in plant disease specimen room of Guizhou Academy of Forestry.

An interesting questions arose at the end of the study: in Luodian county and its neighbouring areas, an traditional important woody oil plant species, Tung-oil tree (Aleurites fordii Hemsl.), had been seriously damaged by a notorious root rot disease since 1980's, and the causal agent was also identified as Fusarium solani (Chen and Xiao 1989), resulting in the breakdown of the Tong-oil industry since then. Are the pathogen Fusarium solani causing root rot of Jatropha curcas is the same as the one causing root rot of Tung-oil tree? Will the root rot disease of Jatropha curcas be also destructive to the Jatropha plantation, thereby the jatropha industry in the future? Since it is well known that Fusarium solani is in fact a complex species and has different formae speciales pathogenic on specific hosts (Booth 1971), a further and much detailed study on this pathogen is urgently needed, including its host-specificity, bio-ecological characteristics, as well as its relevant management strategy, etc.

Acknowledgement This study was supported by the Guizhou Provincial Science Foundation Project (QKH J[2007]2070) and the Guizhou Provincial Key Research Project (QKH NY[2009]3065). Special thanks to Dr. Keith Seifert from Agriculture \& Agri-Food Canada for his support in the identification of Fusarium species by kindly offering relevant materials and software.

\section{References}

Booth C (1960) Studies of Pyrenomycetes. V. Nomenchlature of some Fusaria in relation to their nectrioid perithecia states. Pages 1-6 in Commonwealth Mycological Institute. Mycological Papers 74, 16p

Booth C (1971) The genus Fusarium. CAB International, Wallingford, $236 p$

Booth C (1977) Fusarium, Laboratory guide to the identification of major species. Commonwealth Mycological Institute. Ferry Lane. Kew, Surrey, England, $58 \mathrm{pp}$

Chen S, Xiao Y (1989) A new forma speciales of Fusarium solani causing root-rot of Tung-oil tree. Sci Silvae Sinicae 25(2):113-119

Dingley JM (1951) The hypocreales of New Zealand II. The Genus Nectria. Trans R Soc NZ 79(Part 2):177-202

Kaushik N, Sharma S, Kaushik JC (2001) Fusarium moniliforme causing root rot of jatropha. Indian Phytopathol 54(2):275

Latha P, Prakasam V, Kamalakannan A, Gopalakrishnan C, Raguchander T, Paramathma M, Samiyappan R (2009) First report of Lasiodiplodia theobromae (Pat.) Griffon \& Maubl. causing root and collar rot disease of physic nut (Jatropha curcas L.) in India. Australas Plant Dis Notes 4:19-21

Pereira OL, Dutra DC, Dias LAS (2009) Lasiodiplodia theobromae is the causal agent of a damaging root and collar rot disease on the biofuel plant Jatropha curcas in Brazil. Australas Plant Dis Notes 4:120-123

Wei J (1979) A manual for fungi identification [M]. Shanghai Science \& Technology Press, Shanghai, p 780 